Quim. Nova, Vol. 33, No. 7, 1510-1513, 2010

\title{
CONSTITUINTES QUÍMICOS E EFEITO ECOTOXICOLÓGICO DO ÓLEO VOLÁTIL DE FOLHAS DE Eucalyptus urograndis (MIRTACEAE)
}

\author{
Fabíola Oliveira Lino de Araújo e Arnola Cecília Rietzler \\ Departamento de Biologia Geral, Instituto de Ciências Biológicas, Universidade Federal de Minas Gerais, 31270-901 Belo \\ Horizonte - MG, Brasil \\ Lucienir Pains Duarte*, Grácia Divina de Fátima Silva e Fernando Carazza \\ Departamento de Química, Instituto de Ciências Exatas, Universidade Federal de Minas Gerais, 31270-901 Belo Horizonte - MG, Brasil \\ Sidney Augusto Vieira Filho \\ Departamento de Farmácia, Escola de Farmácia, Universidade Federal de Ouro Preto, 35400-000 Ouro Preto - MG, Brasil
}

Recebido em 19/10/09; aceito em 19/3/10; publicado na web em 29/6/10

\begin{abstract}
CHEMICAL CONSTITUENTS AND ECOTOXICOLOGICAL EFFECT OF THE VOLATILE OIL FROM LEAVES OF Eucalyptus urograndis (MIRTACEAE). The volatile oil from the leaves of E. urograndis was analyzed by GC and GC-MS. It was identified 10 compounds in which, orto-cimene (41.4\%) and 1,8-cineol (25.8\%) were the main constituents. The induction of deleterious effect to aquatic organisms due to the presence of volatile oil lixiviated from E. urograndis leaves was studied using Daphnia laevis and D. similis as bioindicators. Through the results of toxicological tests it was possible to show that the litterbag of E. urograndis represents a risk factor for the aquatic ecosystem of lakes and rivers that are in the surrounding area of large scale Eucalyptus plantations. The method can be used for monitor the quality of these types of aquatic environments.
\end{abstract}

Keywords: Eucalyptus urograndis; aquatic ecotoxicological effect; Daphnia sp.

\section{INTRODUÇÃO}

A família Mirtaceae compreende cerca de 140 gêneros, com aproximadamente 3.000 espécies, divididas em 2 subfamílias Myrtorideae e Leptospermoideae, e tem distribuição geográfica predominante na América tropical e Austrália. Além da sua grande importância nos ecossistemas brasileiros, membros dessa família apresentam propriedades farmacológicas. ${ }^{1}$

Existem centenas de espécies do gênero Eucalyptus, no entanto, poucas são destinadas ao plantio em grande escala, por não apresentarem características comerciais desejáveis. Segundo a Food and Agriculture Organization (2005), Eucalyptus grandis e E. urophylla representam as espécies mais utilizadas no plantio extensivo. A espécie Eucalyptus urophylla é nativa de algumas ilhas orientais do arquipélago de Sonda, situadas ao norte da Austrália. ${ }^{2}$ Existem cultivos florestais que utilizam espécies geneticamente modificadas, como, por exemplo, E. urograndis, que é um híbrido de E. urophylla e E. grandis, amplamente utilizado em plantios florestais em Minas Gerais. ${ }^{3}$ Algumas espécies atingem alturas superiores a $70 \mathrm{~m}$ sendo que $E$. grandis pode atingir, excepcionalmente, $100 \mathrm{~m}$ de altura e é considerada a espécie florestal latifoliada mais alta do mundo. ${ }^{4}$ Os óleos essenciais isolados de Eucalyptus ocorrem principalmente nas folhas onde são produzidos e armazenados em células secretoras. ${ }^{5}$ Bruneton $^{5}$ e Guenter ${ }^{6}$ relatam que o óleo essencial das folhas de plantas deste gênero é um líquido incolor ou amarelado, por vezes acastanhado ou esverdeado, fluido, com cheiro forte, aromático e de sabor picante, apresentando como principais compostos isolados, o 1,8-cineol (eucaliptol), piperitona, felandreno e aldeídos voláteis. Vários constituintes do óleo essencial de folhas de Eucalyptus apresentam efeitos tóxicos. ${ }^{6}$ Durante o período de chuvas, folhas de eucaliptos são lixiviadas para rios e lagoas, levando para dentro do leito destes os seus constituintes químicos, incluindo os óleos essenciais. A presença desses óleos no meio aquoso representa um

\footnotetext{
*e-mail: lucienir@ufmg.br
}

risco potencial de efeitos prejudiciais aos organismos aquáticos. ${ }^{7}$

Como parte de um programa de pesquisa que tem como objetivo identificar impactos ambientais causados pela serapilheira de uma das espécies de Eucalyptus mais utilizadas em Minas Gerais e possíveis soluções, investigou-se o rendimento e a composição química do óleo volátil de E. urograndis, obtido de folhas senescentes secas ou após exposição em ambiente aquático natural. Para verificar o efeito sazonal sobre o rendimento, a variação e composição do óleo volátil da serapilheira de $E$. urograndis, determinou-se o teor deste na massa de folhas senescentes secas, obtida em períodos de inverno e de verão. Estes mesmos parâmetros também foram estudados nos óleos obtidos de folhas submetidas a diferentes períodos de incubação por imersão, em diferentes períodos de tempo, na Lagoa Palmeirinha, situada na região do médio Rio Doce, Município de Dionísio, próximo ao Parque Estadual do Rio Doce, Minas Gerais, Brasil.

O objetivo foi verificar, através de experimentos em laboratório, se a liberação desse óleo volátil na água causa algum efeito deletério à biota aquática, utilizando-se dafnídeos como bioindicadores.

\section{PARTE EXPERIMENTAL}

\section{Procedimentos de campo}

Folhas de E. urograndis foram coletadas da serapilheira obtida do viveiro de mudas provenientes da Celulose Nipo-Brasileira (Cenibra). A monocultura dessa espécie encontrava-se no talhão 170 (CAF0011, 2004) na propriedade da Companhia Agro Florestal, situada no Município de Dionísio, região do médio Rio Doce, próximo ao Parque Estadual do Rio Doce, em Minas Gerais.

As coletas das amostras de folhas senescentes foram realizadas nos meses de junho de 2006 e janeiro de 2007, correspondentes aos períodos de inverno e verão, na região de Minas Gerais. Foram coletadas folhas verdes, apenas em junho (FVi) e folhas da serapilheira, tanto no período de inverno (junho/06) quanto de verão (janeiro/07) (FSi e FSv). Uma parte das folhas secas foi armazenada 
em litterbags de $20 \times 15 \mathrm{~cm}$ e malha de $1 \times 1 \mathrm{~cm}$, amarrados linearmente em uma corda e deixados imersos na lagoa Palmeirinha, a aproximadamente $1,0 \mathrm{~m}$ de profundidade e $10 \mathrm{~m}$ de distância da margem. Após 40 dias de incubação, metade dos litterbags foi retirada, nos momentos correspondentes aos períodos de primeira decomposição de inverno e de verão (1DECi e 1DECv). Após 76 dias de incubação, foram retirados os litterbags restantes, correspondentes aos períodos de segunda decomposição de inverno e verão (2DECi e $2 \mathrm{DECV})$.

\section{Procedimentos de laboratório}

\section{Extração do óleo}

Folhas verdes e folhas senescentes secas de E. urograndis foram, separadamente, fragmentadas e depois submetidas à extração dos óleos voláteis, em aparelho Cleavenger modificado. Após incubação na lagoa por períodos determinados, as folhas foram lavadas com água destilada e secadas ao ar livre e à sombra, fragmentadas e depois submetidas à extração dos óleos voláteis. A porcentagem do peso seco das amostras e o rendimento do óleo volátil encontram-se listados na Tabela 1.

Tabela 1. Rendimento do óleo volátil obtido de folhas de E. urograndis coletadas, após incubação na Lagoa Palmeirinha, em Minas Gerais, nos períodos de inverno e verão

\begin{tabular}{|c|c|c|c|}
\hline \multirow{2}{*}{ Folhas senescentes } & \multirow{2}{*}{$\begin{array}{l}\text { Peso seco } \\
(\mathrm{g})\end{array}$} & \multicolumn{2}{|c|}{ Rendimento do óleo } \\
\hline & & $(\mathrm{mg})$ & $(\%)$ \\
\hline \multicolumn{4}{|l|}{ Coleta / Inverno } \\
\hline Folhas secas (FSi) & 116,3 & 855,8 & 0,74 \\
\hline 40 dias de incubação (1DECi) & 34,0 & 236,6 & 0,69 \\
\hline 76 dias de incubação (2DECi) & 23,4 & 70,3 & 0,30 \\
\hline \multicolumn{4}{|l|}{ Coleta / Verão } \\
\hline Folhas secas (FSv) & 116,2 & 869,7 & 0,75 \\
\hline 40 dias de incubação (1DECv) & 30,0 & 111,8 & 0,37 \\
\hline 76 dias de incubação (2DECv) & 30,1 & 59,6 & 0,20 \\
\hline
\end{tabular}

As amostras recém-cortadas foram submetidas à hidrodestilação por um período de $4 \mathrm{~h}$. Os óleos essenciais extraídos foram separados da água utilizando-se éter etílico; a fase orgânica foi tratada com sulfato de sódio anidro, filtrada e o solvente foi removido em evaporador rotativo. O óleo residual foi acondicionado em frasco eppendorf branco e mantido sob refrigeração a $0{ }^{\circ} \mathrm{C}$ para posteriormente ser analisado por CGAR e CG/EM ou utilizado em testes ecotoxicológicos.

\section{Análise química do óleo}

O óleo de folhas de E. urograndis foi analisado por cromatografia gasosa, realizada em cromatógrafo GC HP5890, com injetor automático HP5989A, do Departamento de Química, UFMG, equipado com detector FID e coluna $\mathrm{HP}-5$, utilizando $\mathrm{H}_{2}$ como gás de arraste. Condições de análise: $50{ }^{\circ} \mathrm{C} 5{ }^{\circ} \mathrm{C} / \min 290{ }^{\circ} \mathrm{C}$; detector 290 ${ }^{\circ} \mathrm{C}$; injetor $280{ }^{\circ} \mathrm{C}$. E, também por cromatografia gasosa acoplada a espectrômetro de massas Varian Modelo 4000, do CETEC-MG; coluna: HP-1; gás de arraste hélio; mesmas condições de análise; impacto eletrônico (EI) a 70 eV.

\section{Identificação dos constituintes do óleo}

A identificação dos componentes do óleo de folhas de E. urograndis (Tabela 2) foi baseada no índice de retenção de Kovats (IK), calculado em relação aos tempos de retenção de uma série homóloga de $n$-alcanos, no padrão de fragmentação observado nos espectros de massas e por comparação destes com dados da literatura. ${ }^{8}$

\section{Ensaios ecotoxicológicos}

O óleo das amostras foliares de E. urograndis foi diluído em água de cultivo em concentrações crescentes $\left(\mu \mathrm{L} 100 \mathrm{~mL}^{-1}\right)$ e, em seguida, submetido a ensaios ecotoxicológicos pelo método de toxicidade aguda, utilizando-se Daphnia similis e D. laevis como organismos teste. Os experimentos foram realizados de acordo com as regras estabelecidas pela Associação Brasileira de Normas Técnicas. ${ }^{9}$

Para os testes, foram selecionados indivíduos neonatos obtidos de culturas desses cladóceros existentes no Laboratório de Ecotoxicologia do ICB/UFMG. Todos os ensaios foram realizados em duplicata. Os resultados dos ensaios ecotoxicológicos foram processados pelo programa GW Basic utilizando o método estatístico Trimmed Spearman-Karber, determinando a CE50 de cada amostra. As diferenças significativas entre os valores de CE50 foram determinadas utilizando fórmula sugerida por Zagatto e Bertoletti. ${ }^{7}$

\section{RESULTADOS E DISCUSSÃO}

Vitti e Brito 5 relataram que dentre aproximadamente 600 espécies de Eucalyptus, pouco mais de 200 já foram estudadas em relação à produção e ao rendimento do óleo volátil. De acordo com esses autores, as principais espécies produtoras de óleo essencial no Brasil, considerando o rendimento foliar a partir de folhas secas, são $E$. citriodora (1,0 a 1,6\%), E. globulus (1,7 a 5\%) e o E. staigeriana $(1,2$ a $1,5 \%)$.

No presente estudo, o rendimento dos óleos essenciais de E. urograndis em relação à massa de folhas senescentes secas foi de $0,74 \%$ para o período de inverno e de $0,75 \%$ para o período de verão, indicando que não houve diferença significativa associada à estação do ano. Este fato pode ser justificado pela observação de que folhas na serapilheira recebem pouca incidência de luz solar, independentemente da época do ano, devido à sombra existente na parte inferior da monocultura de eucaliptos. Verificou-se, no entanto, que o rendimento foi bastante significativo em se tratando de folhas secas já que de acordo com Vitti e Brito, ${ }^{5}$ dependendo da espécie de Eucalyptus analisada, o teor de óleo em folhas verdes frescas varia entre 1 a $5 \%$. Após o primeiro intervalo de 40 dias de incubação na lagoa Palmeirinha, verificou-se um teor de 0,69\% de óleos essenciais nas folhas coletadas no inverno e $0,37 \%$ naquelas colhidas no verão. Neste caso, observou-se que no período de verão há uma maior perda de óleo, uma vez que a incidência de luz solar e a temperatura são maiores nesta época e podem provocar a volatilização dos constituintes mais voláteis do óleo. Depois de 76 dias de incubação na lagoa, encontrou-se $0,30 \%$ de óleo volátil nas folhas coletadas no inverno e 0,20\% nas obtidas no verão (Tabela 1). Pode-se verificar que mesmo após 76 dias em contato com a água, as folhas ainda apresentaram um conteúdo significativo de óleo volátil em sua composição. Os resultados demonstraram, ainda, que um maior tempo de incubação de folhas na lagoa provocou maior liberação de constituintes do óleo volátil. Esse processo pode acarretar danos ao sistema aquático, mas mesmo após este período ainda há óleo volátil nas folhas, implicando em um potencial efeito danoso para os animais que se alimentam deste material em decomposição, que é carreado para o recurso hídrico.

Todas as amostras de óleo volátil obtidas de folhas, incluindo folhas verdes, foram analisadas por CGAR para determinação da sua constituição química.

A análise do óleo volátil das folhas de E. urograndis mostrou uma predominância de mono e sesquiterpenos e demonstrou que a constituição química de todas as amostras foi bastante similar mesmo naquelas mantidas incubadas na lagoa por 76 dias (Tabela 2).

Esse resultado indicou que o potencial toxicológico dos óleos essenciais foliares de E. urograndis mantém-se estável, mesmo durante o processo de decomposição ocorrido nos 76 dias de imersão, o que representa um risco ao ecossistema aquático. 
Tabela 2. Porcentagem de constituintes do óleo volátil em folhas senescentes de E. urograndis, detectados por CGAR

\begin{tabular}{|c|c|c|c|c|c|c|c|}
\hline \multirow[t]{2}{*}{ Constituinte } & \multirow{2}{*}{$\begin{array}{c}\mathrm{TR} \\
(\mathrm{min})\end{array}$} & \multicolumn{2}{|c|}{ Índice de Kovats } & \multicolumn{4}{|c|}{ Porcentagem (\%) de óleos essenciais em folhas de E. urograndis } \\
\hline & & Calc & Literatura $^{9}$ & $\mathrm{FVi}$ & FSi & 1DECi & 2DECi \\
\hline Orto-cimeno & 8,16 & 1024 & 1022 & 41,4 & 25,3 & 31,4 & 25,1 \\
\hline 1,8-Cineol & 8,28 & 1035 & 1033 & 25,8 & 9,3 & 17,9 & 15,8 \\
\hline $\mathrm{NI}$ & 9,13 & 1046 & - & 7,5 & 2,4 & 6,3 & 4,6 \\
\hline $\mathrm{NI}$ & 12.65 & 1173 & - & 3,4 & 4,0 & 2,0 & 1,6 \\
\hline$\alpha$-Terpineol & 13,04 & 1188 & 1189 & 1,4 & 2,5 & 1,1 & 1,3 \\
\hline$p$-Cimen-7-ol & 15,77 & 1287 & 1287 & 1,3 & 3,7 & 1,1 & 1,0 \\
\hline Timol & 16,06 & 1296 & 1290 & 0,8 & 2,5 & 0,7 & 0,6 \\
\hline 3-Metoxi-acetofenona & 16,23 & 1302 & 1297 & 1,2 & 3.4 & 1,0 & 0,8 \\
\hline Acetato de $\alpha$-terpinila & 17,59 & 1353 & 1350 & 1,4 & 2,0 & 1,6 & 2,5 \\
\hline NI & 19,58 & 1424 & - & 1,0 & 1,7 & 3,1 & 3,1 \\
\hline NI & 20,62 & 1462 & - & 1,8 & 2,4 & 1,4 & 1,5 \\
\hline NI & 21,96 & 1510 & - & nd & 1,0 & 1,2 & 2,7 \\
\hline NI & 22,27 & 1521 & - & 1,0 & 1,5 & 1,5 & 1,6 \\
\hline Germacreno- $\gamma$-4-ol & 23,70 & 1573 & 1574 & 1,2 & 4,6 & 2,0 & 2,8 \\
\hline NI & 23,87 & 1579 & - & 2,9 & 6,7 & 2,8 & 4,0 \\
\hline Davanona & 24,07 & 1587 & 1586 & 1,2 & 3,5 & 3,1 & 4,2 \\
\hline NI & 24,30 & 1595 & - & nd & 0,7 & 0,9 & 1,4 \\
\hline 1,10-Di-epi-cubenol & 24,65 & 1611 & 1614 & 1,8 & 3,1 & 2,3 & 3,3 \\
\hline NI & 24,85 & 1615 & - & 2,2 & 4,2 & 3,0 & 4,1 \\
\hline NI & 24,92 & 1618 & - & 1,1 & 2,2 & 1,8 & 2,7 \\
\hline NI & 25,25 & 1630 & - & nd & 1,3 & 1,0 & 1,4 \\
\hline Total & & & - & 98,4 & 84,6 & 87,2 & 86,1 \\
\hline
\end{tabular}

Folhas verdes (FVi), senescentes secas (FSi) e após 40 (1DECi) e 76 (2DECi) dias de incubação na Lagoa Palmeirinha; NI = não identificado; nd = não detectado.

Foram identificados 10 constituintes nos óleos essenciais analisados. A soma do teor desses óleos correspondeu a aproximadamente $50 \%$ do total encontrado nas amostras FSi, 1DECi e 2DECi. Dos 10 constituintes identificados no óleo volátil de E. urograndis, 6 deles, o orto-cimeno, 1,8-cineol, $\alpha$-terpineol, timol, germacreno- $\gamma$-4-ol e o 1,10-di-epi-cubenol, são importantes compostos utilizados como fragrâncias e aromas. A propriedade inseticida dos monoterpenos 1,8 -cineol e $\alpha$-terpineol e dos sesquiterpenos germacreno- $\gamma$-4-ol e 1,10-di-epi-cubenol é relatada na literatura. ${ }^{6}$ Além disso, de acordo com estudos realizados por Franco e colaboradores, ${ }^{10} \mathrm{o}$ óleo essencial de Eucalyptus apresenta potencial antimicrobiano frente às leveduras e bactérias Gram-positivas e Gram-negativas.

Segundo Ogunwande e colaboradores, ${ }^{10}$ a ausência de 1,8-cineol representa uma peculiaridade em E. grandis. Por outro lado, Estanislau e colaboradores ${ }^{10}$ relataram a presença deste monoterpeno no óleo de $E$. grandis, na concentração de 7,74\%. Nesse trabalho verificou-se a presença de uma maior porcentagem $(25,3 \%)$ desse constituinte no óleo volátil de folhas secas de E. urograndis. Por outro lado, o óleo essencial de $E$. grandis apresenta elevados teores de $\alpha$-pineno $(44,7 \%)$ e de $\beta$-pineno (30,5\%). ${ }^{10}$ Esses dois constituintes não foram detectados no óleo obtido de folhas de E. urograndis.

O 1,8-cineol, encontrado no óleo volátil das folhas de E. urograndis, apresenta propriedades farmacológicas, tais como ação anestésica, antibronquítica, antisséptica, bactericida, expectorante e, também, atividades herbicida e insetífuga, ${ }^{11}$ sendo, em função disso, muito utilizado na indústria farmacêutica. Até o momento, a principal espécie utilizada para a obtenção de cineol no Brasil é o E. globulus. Algumas referências citam a extração de cineol a partir de E. smithii. ${ }^{5}$

No óleo volátil de folhas de E. urograndis também foi identificado o timol (5), um terpeno aromático que possui propriedades anti-helmíntica, anti-inflamatória, antisséptica, bactericida, fungicida, larvicida e vermicida. ${ }^{11}$
O potencial ecotoxicológico dos óleos essenciais foi avaliado de acordo com as normas da Associação Brasileira de Normas Técnicas (ABNT). ${ }^{9}$ Os testes de toxicidade foram realizados em laboratório, utilizando Daphnia laevis e Daphnia similis como bioindicadores. De acordo com a literatura, cladóceros do gênero Daphnia são espécies sensíveis na detecção de efeitos deletérios de substâncias químicas a organismos aquáticos. Um importante argumento para o uso de Daphnia spp, em estudos ecotoxicológicos reside no fato de ser representativa em muitos corpos d'água. ${ }^{12}$ Neste contexto, foi importante a utilização de Daphnia laevis, nativa do Brasil, e sua comparação com $D$. similis, espécie padronizada exótica.

Em todos os testes realizados, foram observados efeitos de toxicidade, sendo que o de maior intensidade foi provocado pelo óleo obtido das folhas que foram mantidas por maior tempo em incubação na lagoa (2DECi, Tabela 3). Constatou-se também que a toxicidade do óleo obtido de folhas aumentou em função do aumento do período de exposição (Tabela 3).

Tabela 3. Valores de CE-50* encontrados para o óleo $\left(\mu \mathrm{L} 100 \mathrm{~mL}^{-1}\right)$ de diferentes amostras foliares de E. urograndis utilizando $D$. laevis e $D$. similis como bioindicadores

\begin{tabular}{lcccc}
\hline \multirow{2}{*}{ Origem do óleo volátil } & \multicolumn{2}{c}{ CE-50 para D. laevis } & \multicolumn{2}{c}{ CE-50 para $D$. similis } \\
& Inverno & Verão & Inverno & Verão \\
\hline Folhas senescentes (FS) & 10,47 & 8,77 & 8,71 & 7,21 \\
Folhas após incubação & & & & \\
40 dias (1DEC) & 6,82 & 8,40 & 7,16 & 9,13 \\
76 dias (2DEC) & 4,89 & 4,56 & 4,78 & 5,38 \\
\hline
\end{tabular}

*Via GW Basic com método estatístico Trimmed Spearman-Karber

O período de imersão das folhas na lagoa Palmeirinha e fatores físicos, como temperatura e luminosidade, e químicos, como alteração 
do $\mathrm{pH}$, juntamente com a ação de micro-organismos decompositores provocaram variações quantitativas na constituição inicial do óleo da serapilheira de E. urograndis (Tabela 2).

Entre os constituintes identificados, verificou-se que o acetato de $\alpha$-terpinila, devanona e o 1,10-di-epi-cubenol tiveram suas concentrações aumentadas na amostra 2DECi, indicando que estes constituintes podem estar relacionados com a maior toxidez apresentada por esta amostra, ou que esse efeito ocorreu devido à formação de compostos tóxicos presentes no óleo volátil e que não foram identificados por CG/EM, neste trabalho.

Observou-se que os valores de CE50 foram numericamente distintos entre as espécies de cladóceros utilizadas e, também, entre os períodos de amostragem (inverno e verão). No entanto, os dados não apresentaram diferenças estatisticamente significativas (Tabela 3 ). Esse fato demonstrou que tanto $D$. laevis como $D$. similis são sensíveis ao óleo da serapilheira de E. urograndis e que podem ser utilizadas como bioindicadores no monitoramento de recursos hídricos existentes no entorno das plantações dessa espécie.

Os dados encontrados indicaram o potencial ecotoxicológico do óleo volátil da serapilheira de E. urograndis e sua persistência no processo de decomposição em meio aquático. Por outro lado, os resultados encontrados para as folhas verdes tornam essa espécie uma planta promissora para a produção de óleo volátil e isolamento de constituintes, tais como orto-cimeno (41,4\%), 1,8-cineol $(25,8 \%)$, destinados às indústrias farmacêutica e de alimentos. Isso, associado à produção de madeira e celulose já existentes em Minas Gerais, propicia um aproveitamento adequado das folhas, com diminuição de possíveis impactos prejudiciais a ecossistemas aquáticos existentes no entorno da área de cultivo em larga escala.

\section{CONCLUSÕES}

Os resultados de testes ecotoxicológicos realizados in vitro demonstraram que a grande quantidade de serapilheira produzida por Eucalyptus urograndis representa um potencial impacto para ambientes aquáticos naturais. Tendo em vista que, nos últimos anos, a utilização dessa espécie em plantio florestal extensivo em Minas Gerais para produção de madeira e celulose vem aumentando, ampliase o risco ecotoxicológico. Através desse trabalho comprovou-se que tanto Daphnia laevis como D. similis podem ser utilizadas como bioindicadores no monitoramento de recursos hídricos existentes no entorno das plantações de E. urograndis.

A análise química do óleo de folhas senescentes de $E$. urograndis demonstrou que a presença de constituintes, tais como orto-cimeno, 1,8-cineol, $\alpha$-terpineol, timol, germacreno- $\gamma$-4-ol e 1,10-di-epicubenol abre perspectivas para a exploração deste material foliar como fonte desses óleos essenciais. Tal fato, além de contribuir para um melhor aproveitamento do insumo florestal, através da associação da produção de madeira com o isolamento de óleos essenciais, irá minimizar possíveis impactos da serapilheira sobre ecossistemas aquáticos.

\section{MATERIAL SUPLEMENTAR}

Está disponível em http://quimicanova.sbq.org.br, na forma de arquivo .PDF com acesso livre.

\section{REFERÊNCIAS}

1. Barroso, G. M.; Guimarães E. F.; Inchaso, C. F.; Costa, C. G.; Peixoto, A. L.; Lima, H. C.; Sistemática de Angiospermas do Brasil, Imprensa UFV: Viçosa, 1984; Limberger, R. P.; Sobral, M.; Henriques, A. T.; Quim. Nova 2004, 27, 916.

2. Scarpinella, G. D.; Dissertação de Mestrado, Universidade de São Paulo, Brasil, 2002.

3. González, E. R.; Andrade, A.; Bertolo, L.; Lacerda, G.; Carneiro, R.; Defávari, V.; Labate, M.; Labate, C.; Funct. Plant Biol. 2002, 29, 97; González, E. R.; Andrade, A.; Bertolo, L.; Lacerda, G.; Carneiro, R.; Defávari, V.; Labate, M.; Labate, C.; Biotecnol. Ciên. \& Desenvolv. 2002, 26, 18.

4. Pryor, L. D.; Biology of Eucalyptus. Studies in Biology, Edward Arnold Ed.: London, 1976.

5. Vitti, A. M. S.; Brito, J. O.; Óleo essencial de Eucalipto, Ed. USP: São Paulo, 2003; Bruneton J.; Elementos de Fitoquimica y de Farmacognosia, Acribia: Zaragoza, 1992; Batista-Pereira, L. G.; Fernandes, J. B.; Corrêa, A. G.; da Silva, M. F. G. F.; Vieira, P. C.; J. Braz. Chem. Soc. 2006, 17, 555.

6. Guenther, E.; The Essencial Oils, Krieger Publication Co.: Malabar, 1972; Panizzi, A. R.; Parra, J. R. P.; Ecologia nutricional de insetos e suas implicações no manejo de pragas, Ed. Manole: São Paulo, 1991; Simões, C. M.; Spitzer, V. Em Farmacognosia: da planta ao medicamento; Simões, C. M. O.; Schenkel, E. P.; Gosmann, G.; Mello, J. C. P.; Mentz, L. A.; Petrovick, P. R., Eds.; 2a . ed., Ed. Universidade/ UFRGS: Porto Alegre, Florianópolis, 2004.

7. Zagatto, P. A.; Bertoletti, E.; Ecotoxicologia aquática: princípios e aplicações, Ed. RiMa: São Carlos, 2006; Miller, G. T.; Environmental Science: Working with the Earth, $11^{\text {th }}$ ed., Publisher Cengage Learning: Belmont, 2007.

8. Adams, R. P.; Identification of Essential Oil Components by gas Cromatography/Mass Spectroscopy, Allured Publishing Corporation: Illinois, 1995.

9. ABNT - Associação Brasileira de Normas Técnicas; Ecotoxicologia Aquática - Toxicidade aguda - Método de Ensaio com Daphnia spp (Cladocera, Crustacea), ABNT: Rio de Janeiro, 2004.

10. Franco, J.; Nakashima, T.; Franco, L.; Boller, C.; Rev. Bras. Farmacogn. 2005, 15, 191; Ogunwande, I. A.; Olawore, N. O.; Adelekek. A.; Konig, W. A.; J. Essent. Oil Res. 2003, 15, 297; Dagne, E.; Bisrat, D.; Alemayehu, M.; Worku, T.; J. Essent. Oil Res. 2000, 12, 457; Estanislau, A. A.; Barros, F. A. S.; Peña, A. P.; Santos, S. C.; Ferri, P. H.; Paula, J. R.; Rev. Bras. Farmacogn. 2001, 11, 95.

11. Cardozo-Filho, L.; Ferrua, F. Q.; Ângela, M.; Meireles, A.; Ciênc. Tecnol. Aliment. 1997, 17, 449; Steffani, E.; Tese de Doutorado, Universidade Federal de Santa Catarina, Brasil, 2003.

12. Leeuwangh, P.; Hydrobiologia 1978, 59, 145. 
CONSTITUINTES QUÍMICOS E EFEITO ECOTOXICOLÓGICO DO ÓLEO VOLÁTIL DE FOLHAS DE Eucalyptus urograndis (MIRTACEAE)

Fabíola Oliveira Lino de Araújo e Arnola Cecília Rietzler

Departamento de Biologia Geral, Instituto de Ciências Biológicas, Universidade Federal de Minas Gerais, 31270-901 Belo Horizonte - MG, Brasil

Lucienir Pains Duarte*, Grácia Divina de Fátima Silva e Fernando Carazza

Departamento de Química, Instituto de Ciências Exatas, Universidade Federal de Minas Gerais, 31270-901 Belo Horizonte - MG, Brasil Sidney Augusto Vieira Filho

Departamento de Farmácia, Escola de Farmácia, Universidade Federal de Ouro Preto, 35400-000 Ouro Preto - MG, Brasil

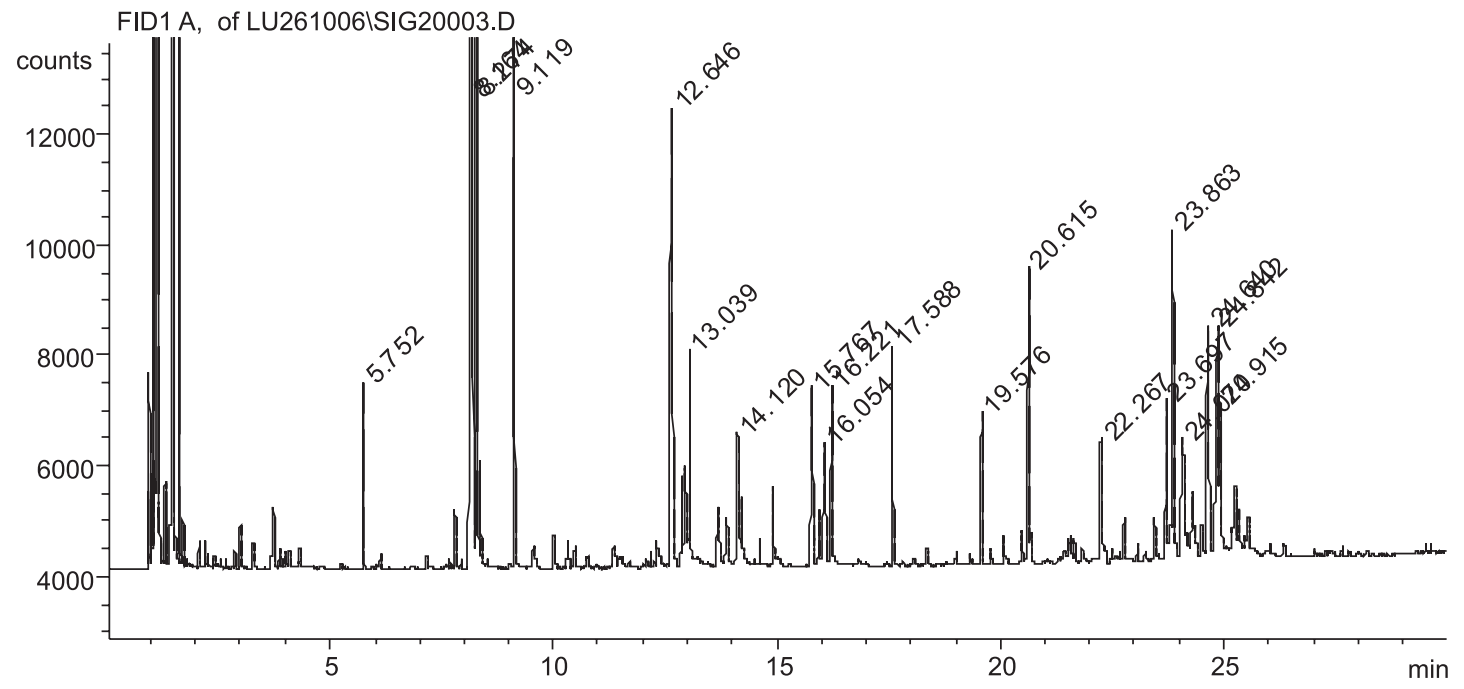

Figura 1S. Cromatograma do óleo volátil das folhas verdes de Eucalyptus urograndis (CGAR) 


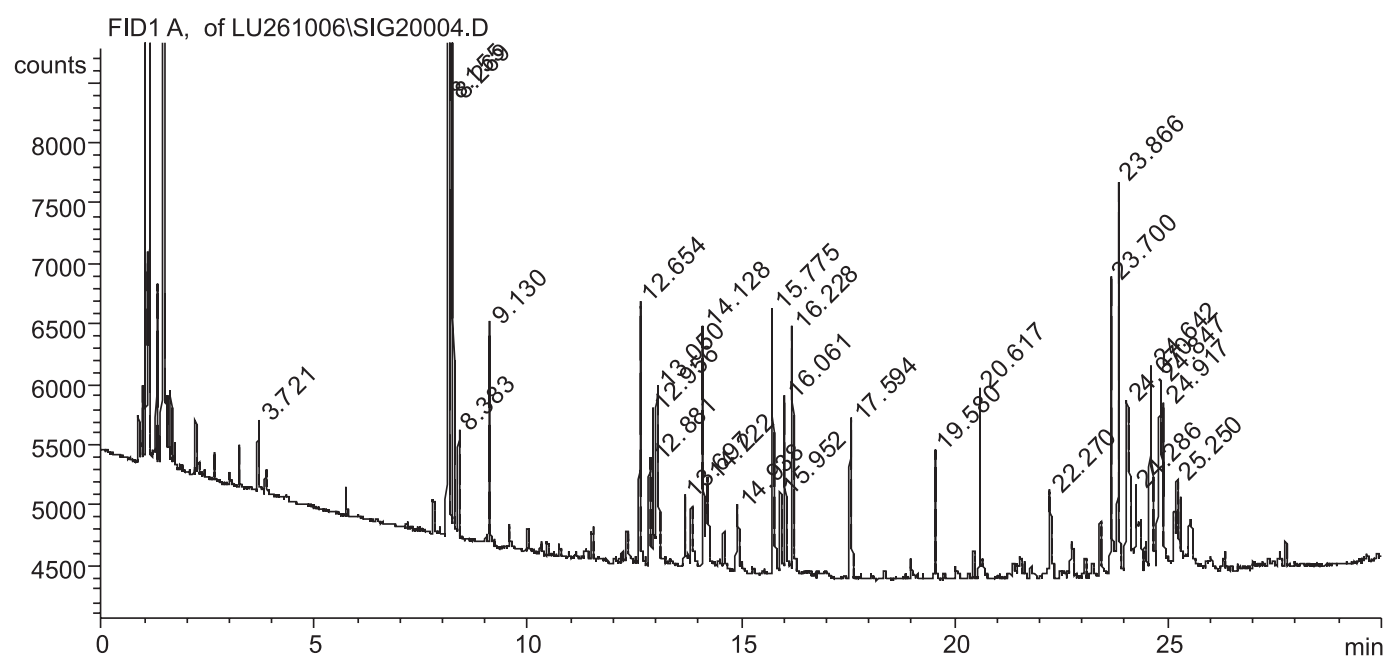

Figura 2S. Cromatograma do óleo volátil das folhas secas de E. urograndis (CGAR)

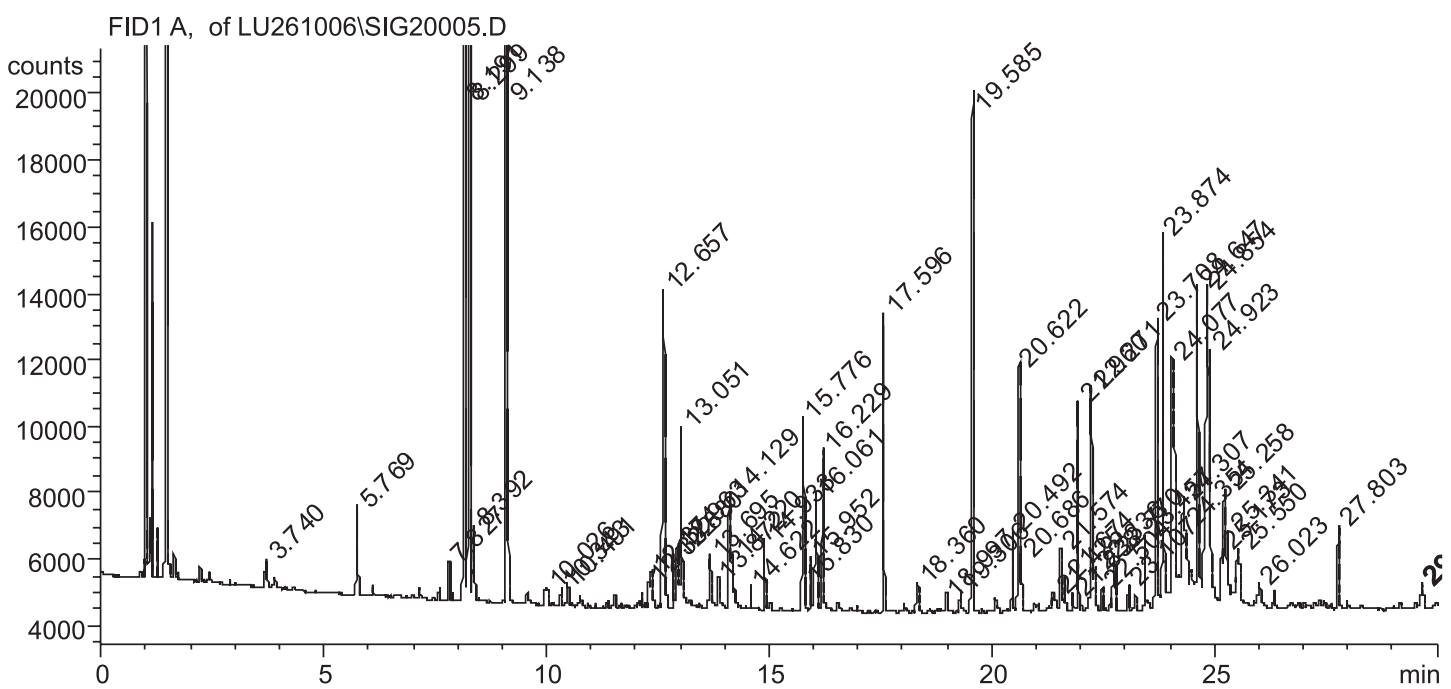

Figura 3S. Cromatograma do óleo volátil das folhas secas $1 D E C$ de E. urograndis (CGAR)

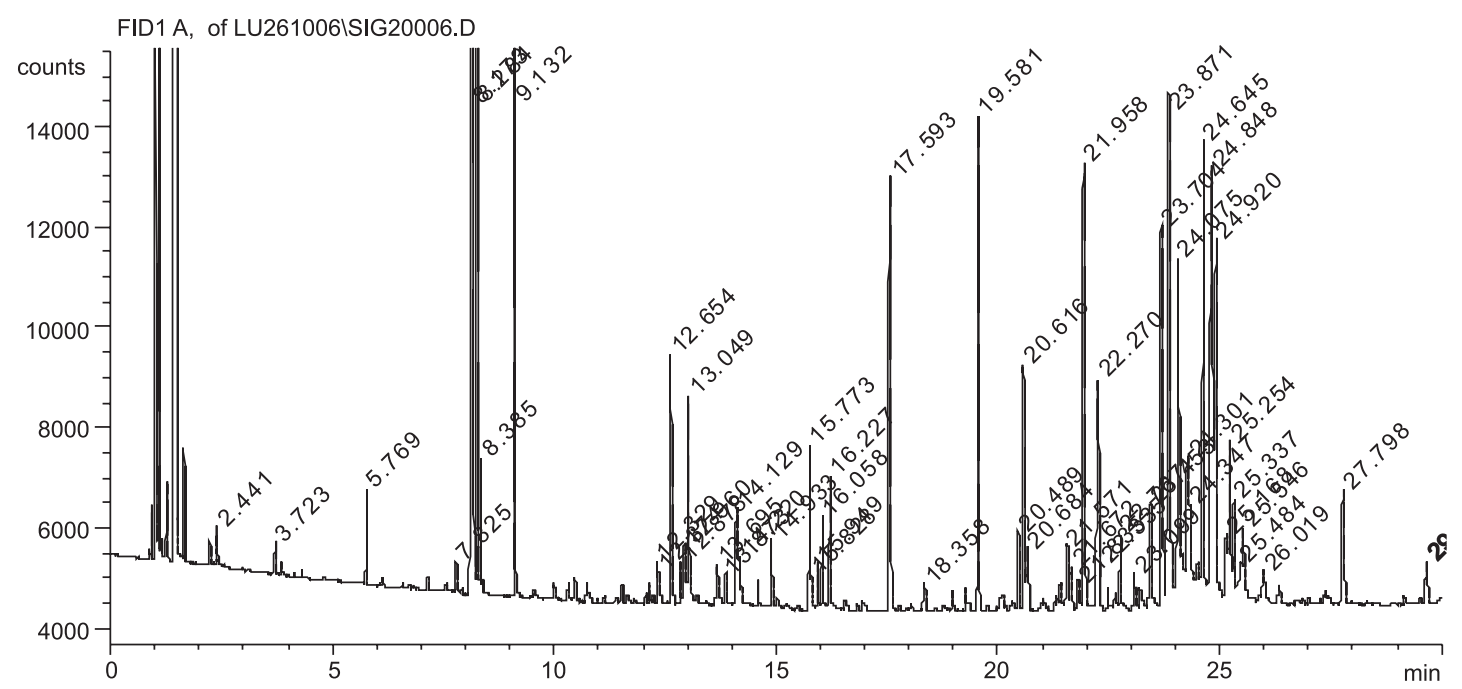

Figura 4S. Cromatograma do óleo volátil das folhas secas $2 D E C$ de E. urograndis (CGAR) 


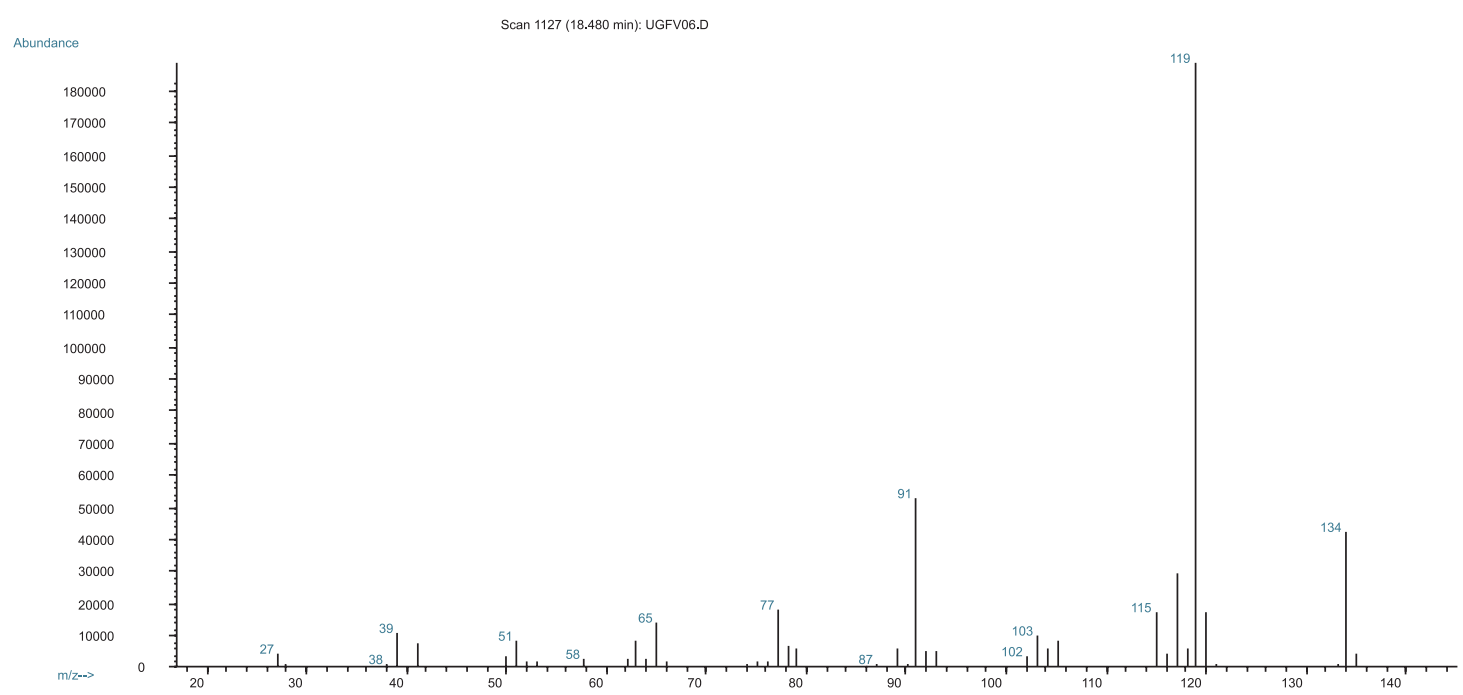

Figura 5S. Espectro de massas do composto com TR 18,48 min (TR 8,16 min no CGAR) (orto-cimeno)

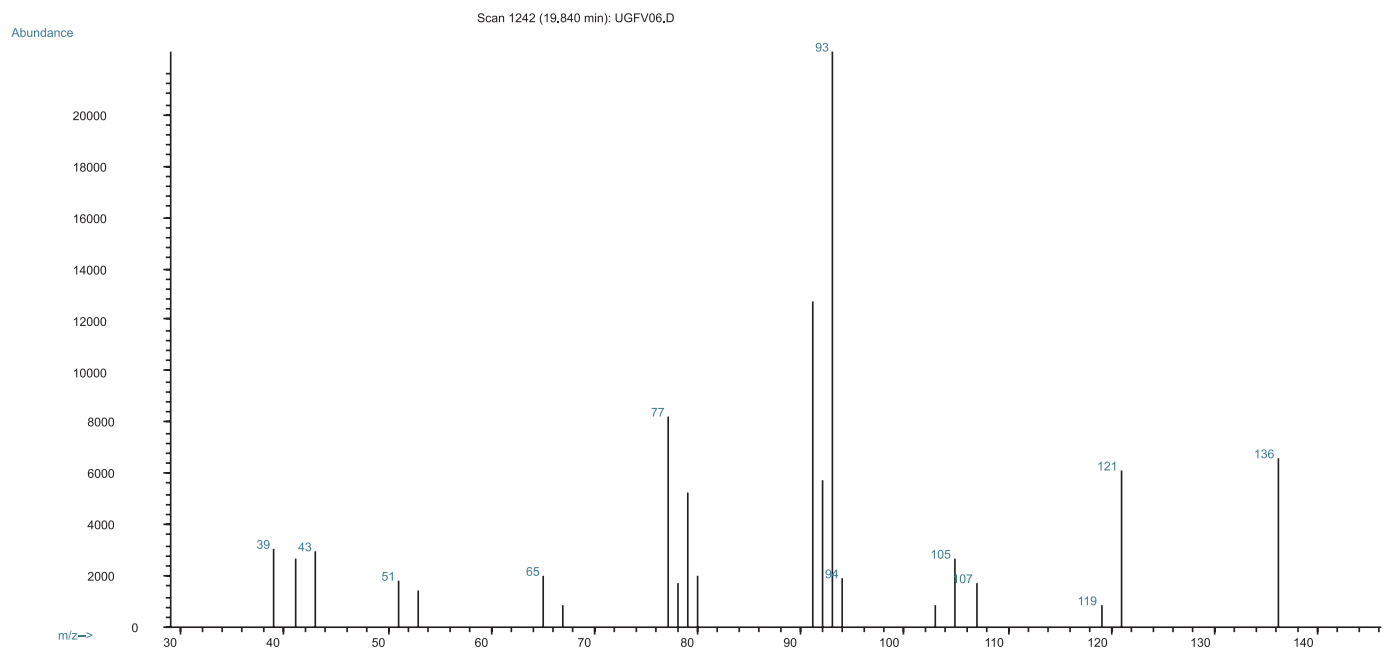

Figura 6S. Espectro de massas do composto com TR 19,84 (TR 9,13 min no CGAR) (NI)

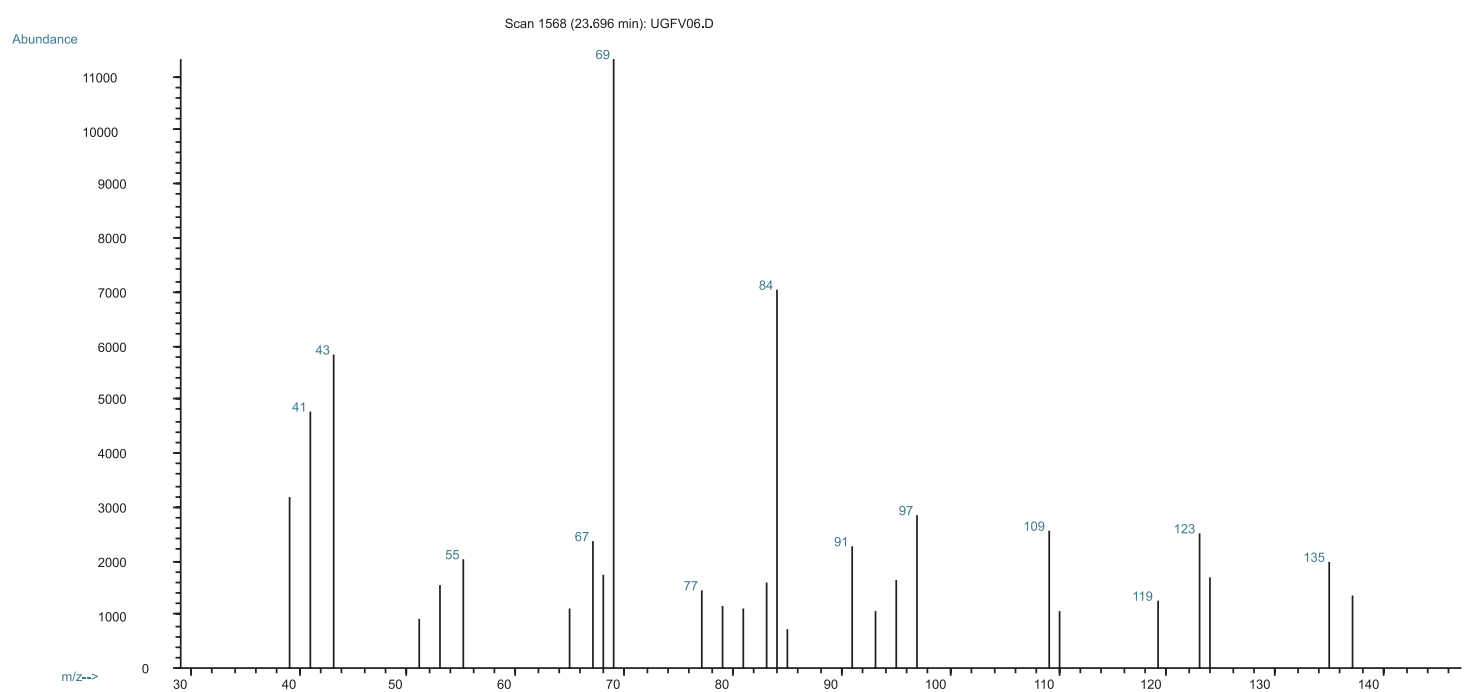

Figura 7S. Espectro de massas do composto com TR 23,70 min (TR 12,65 min no CGAR) (NI) 


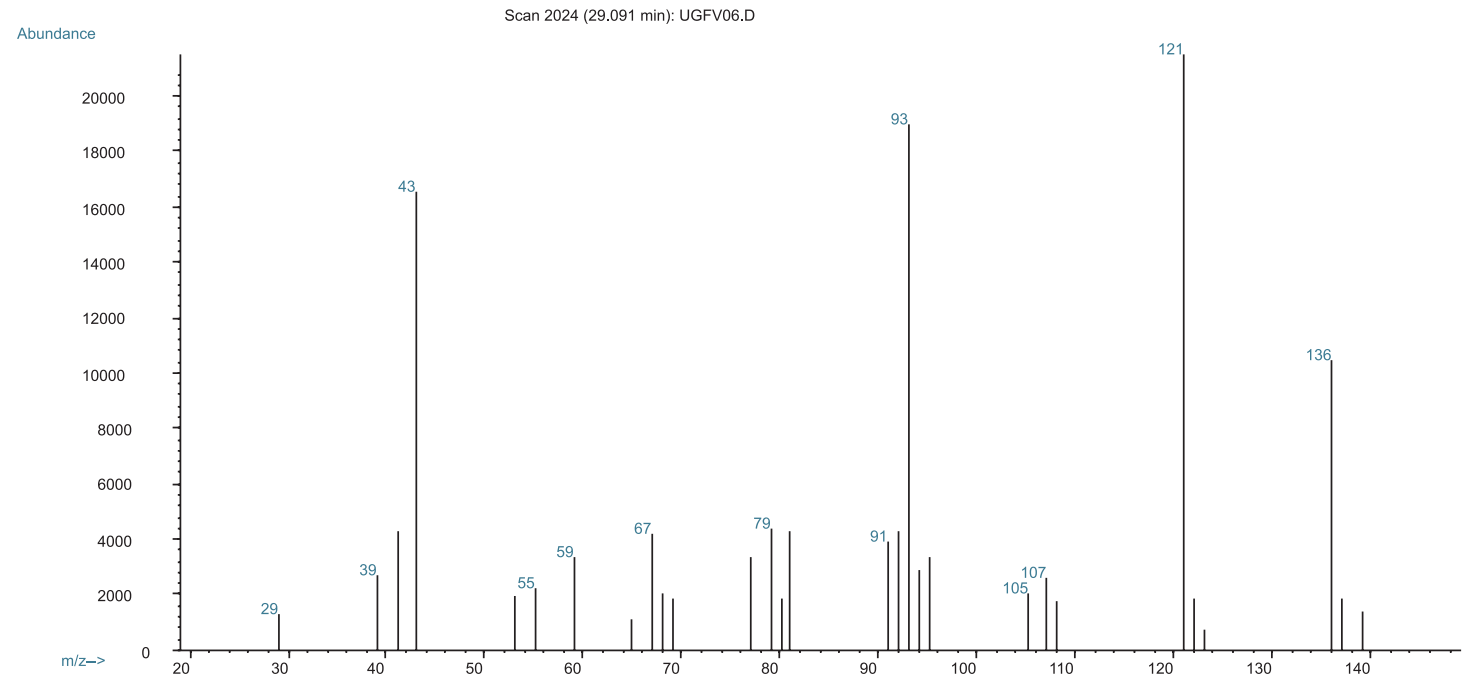

Figura 8S. Espectro de massas do composto com 29,09 $\min$ (TR 17,59 min no CGAR) (Acetato de $\alpha$-terpinila)

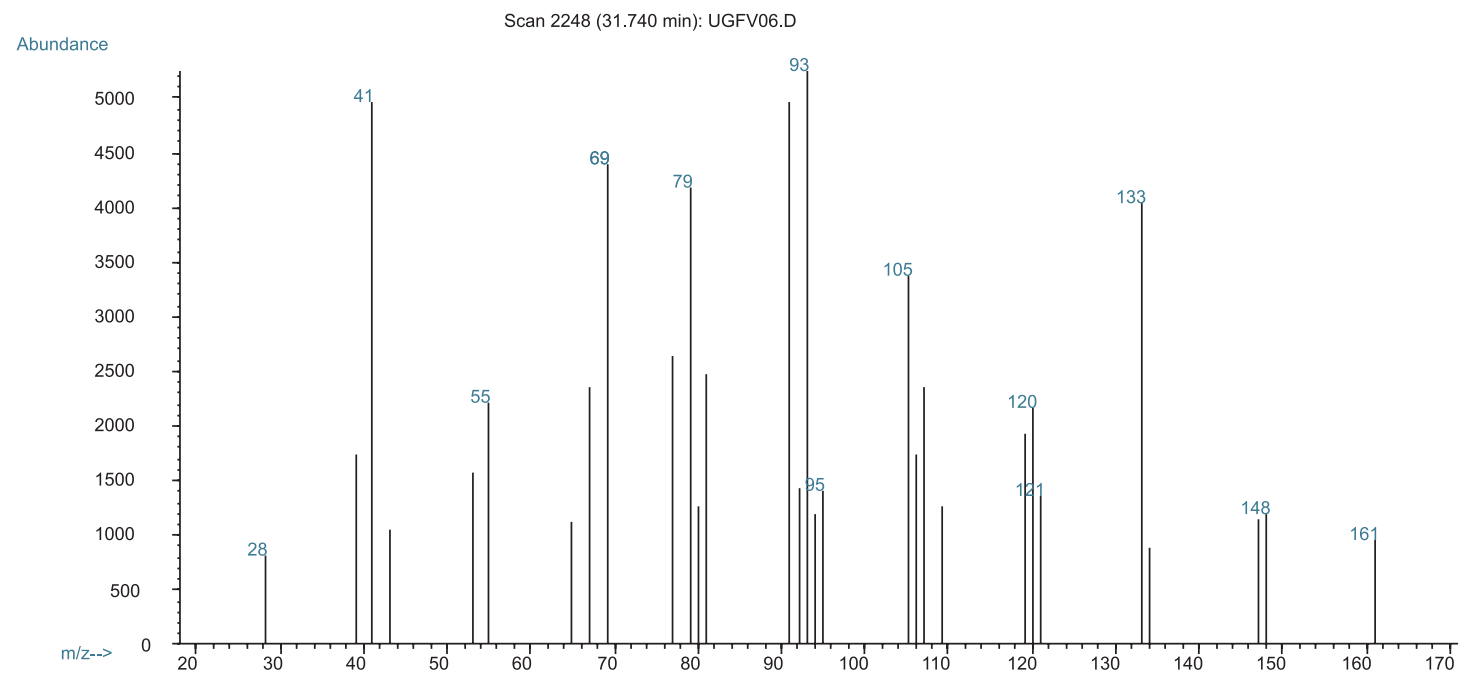

Figura 9S. Espectro de massas do composto com TR 31,74 min (19,58 min no CGAR) (NI)

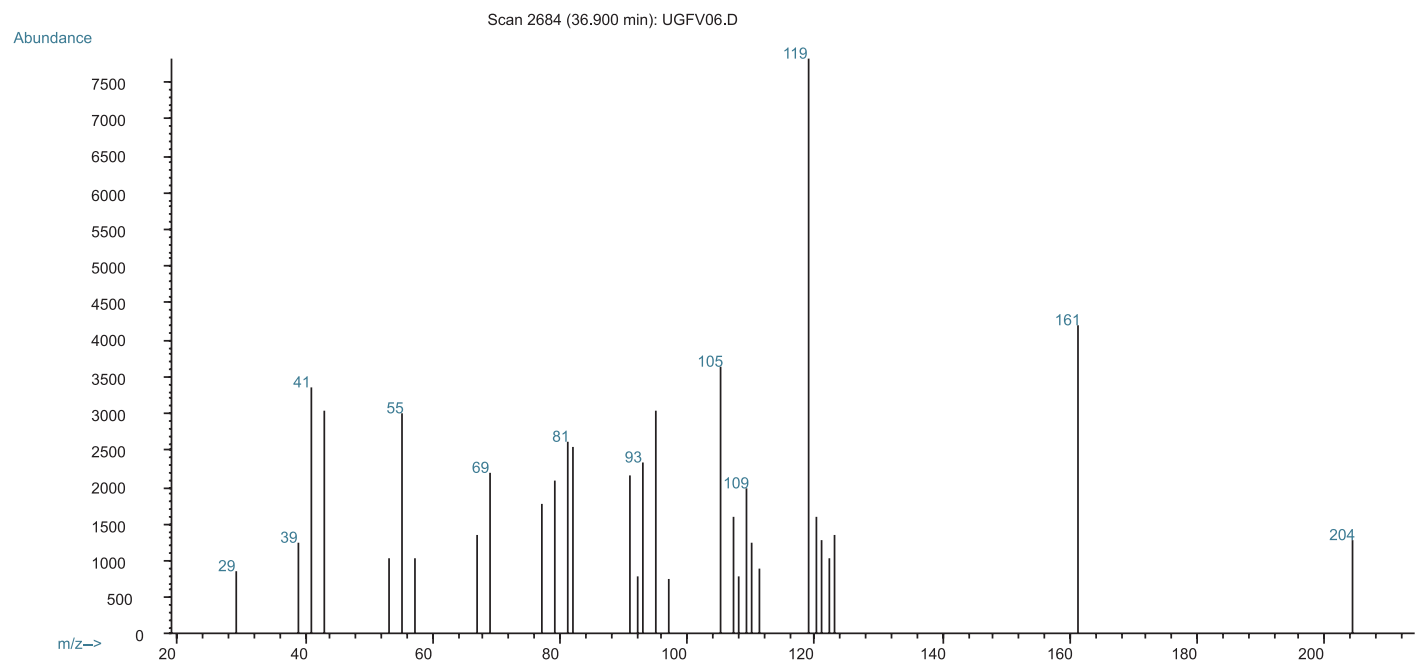

Figura 10S. Espectro de massas do composto com TR 36,90 min (TR 25,25 min) no CGAR (NI) 